\title{
Etanercept, improved dosage schedules and combinations in the treatment of psoriasis: an update
}

\section{Siegfried Segaert}

Department of Dermatology, University Hospital Leuven, Belgium

Correspondence: Siegfried Segaert University Hospital Leuven (UZ Sint-Rafaël), Kapucijnenvoer 33, B-3000 Leuven, Belgium Tel +32 I6 337858

$\mathrm{Fax}+32 \quad 16337859$

Email siegfried.segaert@med.kuleuven.be
This article was published in the following Dove Press journal:

Journal of Inflammation Research

7 August 2009

Number of times this article has been viewed

\begin{abstract}
Etanercept, a subcutaneously administered fully human soluble tumor necrosis factor (TNF) receptor, was initially approved for the treatment of psoriasis at a dose of $25 \mathrm{mg}$ twice weekly in repeated 24-week cycles with the possibility to double the dose in the first 12 weeks of the first cycle. During intermittent treatment, patients retain their ability to respond to etanercept. Recently, a new dosing schedule of etanercept $50 \mathrm{mg}$ once weekly was approved, based on a study in which PASI-75 (75\% improvement of Psoriasis Area and Severity Index) was achieved by $37 \%$ and $71 \%$ of patients at week 12 and 24 . Another study demonstrated a PASI-75 of $57 \%$ and $69 \%$ in pediatric psoriasis patients receiving etanercept $0.8 \mathrm{mg} / \mathrm{kg}$ (up to $50 \mathrm{mg}$ ) once weekly for 12 and 24 weeks respectively, resulting in European approval from age 8 . Based on recent clinical trials, the antipsoriatic effect of etanercept can be markedly increased in combination with acitretin, methotrexate or UVB. The combination with acitretin appears attractive because of its non-immunosuppressive and chemopreventive properties. Etanercept-methotrexate combination therapy is well established in rheumatologic patients. From a long-term perspective, the combination of TNF-inhibitors with phototherapy (photocarcinogenesis) or cyclosporine (carcinogenesis, infections) warrants great caution however. Finally, combination with topical calcipotriol-betamethasone ointment may increase the speed of response to TNF-inhibitors in the first 4 weeks of treatment.
\end{abstract}

Keywords: etanercept, psoriasis, dosing schedules, combination therapy

\section{Introduction}

Tumor necrosis factor (TNF) was first identified in the serum of bacillus Calmette-Guérin-infected mice treated with endotoxin, as a factor inducing necrosis of transplanted tumors. ${ }^{1}$ TNF is a pro-inflammatory cytokine, produced by different cell types including lymphocytes, macrophages and keratinocytes, with pleiotropic effects on numerous tissues. ${ }^{2}$ It is expressed as a membrane-bound trimeric protein that is cleaved by TNF $\alpha$-converting enzyme (TACE) to yield soluble TNF. The actions of TNF are transduced via two types of receptors: TNF-RI initiating a cascade of caspase activation leading to apoptosis and TNF-RII activating the pro-inflammatory transcription factor nuclear factor kappa B (NFאB) through an intracellular signaling pathway. ${ }^{2}$

TNF occupies a pivotal position in the pathogenesis of immune-mediated inflammatory disorders of the joints (rheumatoid arthritis), gut (inflammatory bowel disease) and skin (psoriasis). ${ }^{2}$ The central role of TNF in the pathophysiology of psoriasis was however only fully recognized following the observation that psoriasis fully cleared in a Crohn's disease patient receiving the TNF monoclonal antibody infliximab. ${ }^{3}$ 
Indeed, TNF levels are elevated in psoriasis both in the serum as in the psoriatic skin itself. ${ }^{4}$ Moreover, the increase of TNF in psoriasis patients correlates with the psoriasis area and severity index (PASI) score whereas the reduction of TNF is linked to the clinical response. ${ }^{5}$ Consequently, psoriasis was shown to respond very well to the therapeutic effect of TNF inhibitors. $^{6-7}$

Three TNF antagonists are currently approved for the treatment of psoriasis: etanercept (a soluble receptor fusion protein), infliximab (a mouse-human chimeric monoclonal antibody) and adalimumab (a fully human monoclonal antibody). ${ }^{7}$ Etanercept is a fully human dimeric fusion protein, consisting of two extracellular ligand-binding domains of the human $75 \mathrm{kDa}$ TNF-receptor linked to the Fc portion of human immunoglobulin G1. As a TNF-receptor, etanercept competes for TNF with endogenous TNF receptors. ${ }^{8}$ Bioactive TNF can still be released to some extent from the relatively unstable TNF/etanercept complexes (contrasting with the greater stability of TNF/ infliximab complexes). ${ }^{8}$ Therefore etanercept is a less potent, more balanced TNF-inhibitor than the antibodies infliximab and adalimumab. In contrast to TNF-antibodies, etanercept does not have an antigranuloma effect, explaining its lack of effectiveness in Crohn's disease or Wegener's granulomatosis. ${ }^{9-10}$ At the same time, it does not markedly affect the granulomatous defense against intracellular bacteria such as Mycobacterium tuberculosis. ${ }^{11}$ The halflife of etanercept is 4.3 days, considerably shorter than the antibodies. Consequently, etanercept requires more frequent administrations but is also eliminated more rapidly in case of a serious adverse event (eg, infection). ${ }^{12}$

\section{Effectiveness of etanercept monotherapy in plaque psoriasis}

One phase 2 and two phase 3, placebo-controlled clinical trials have demonstrated that etanercept is an effective and well-tolerated treatment for moderate-to-severe chronic plaque psoriasis. ${ }^{6,13,14}$ The most frequently used endpoint is PASI-75, the percentage of patients achieving a $75 \%$ improvement of their PASI-score, corresponding well to the patients reaching a clear or almost clear status. ${ }^{6}$ The initially registered dosing schedule for etanercept in psoriasis consisted of twice weekly subcutaneous injections of $25 \mathrm{mg}$ etanercept for 24 weeks with the possibility of doubling the dose (to $50 \mathrm{mg}$ twice weekly) during the first 12 weeks. ${ }^{15}$ After each 24-week regiment, another 24-week etanercept regimen ( $25 \mathrm{mg}$ twice weekly) can be started on relapse of the psoriasis. ${ }^{15}$
Table I Overview of PASI-75 responses to etanercept in different dosing schedules and combinations in clinical studies for moderateto-severe plaque psoriasis

\begin{tabular}{|c|c|c|c|}
\hline Dosing schedule & $\begin{array}{l}\text { I2-week } \\
\text { PASI-75 }\end{array}$ & $\begin{array}{l}\text { 24-week } \\
\text { PASI-75 }\end{array}$ & Reference \\
\hline \multicolumn{4}{|c|}{ Etanercept monotherapy in adult psoriasis } \\
\hline $25 \mathrm{mg}$ once weekly & $14 \%$ & $25 \%$ & 6 \\
\hline \multirow[t]{4}{*}{$25 \mathrm{mg}$ twice weekly } & $34 \%$ & $44 \%$ & 6 \\
\hline & $34 \%$ & $45 \%$ & 13 \\
\hline & $30 \%$ & $55 \%$ & 14 \\
\hline & $20 \%$ & $45 \%$ & 34 \\
\hline $50 \mathrm{mg}$ once weekly & $37,5 \%$ & $71 \%$ & 25 \\
\hline $\begin{array}{l}50 \mathrm{mg} \text { twice weekly } 12 \text { weeks + } \\
25 \mathrm{mg} \text { twice weekly } 12 \text { weeks }\end{array}$ & - & $54 \%$ & 13 \\
\hline \multirow[t]{4}{*}{$50 \mathrm{mg}$ twice weekly } & $49 \%$ & $59 \%$ & 6 \\
\hline & $49 \%$ & - & 13 \\
\hline & $47 \%$ & $60 \%$ & 23 \\
\hline & $57 \%$ & - & 22 \\
\hline \multicolumn{4}{|c|}{ Etanercept monotherapy in pediatric psoriasis } \\
\hline $\begin{array}{l}0.8 \mathrm{mg} / \mathrm{kg} \text { once weekly } \\
(\max 50 \mathrm{mg})\end{array}$ & $57 \%$ & $69 \%$ & 26 \\
\hline \multicolumn{4}{|c|}{ Etanercept combination therapy in adult psoriasis } \\
\hline $\begin{array}{l}25 \mathrm{mg} \text { once weekly + acitretin } \\
0.4 \mathrm{mg} / \mathrm{kg} / \text { day }\end{array}$ & $15 \%$ & $44 \%$ & 34 \\
\hline $\begin{array}{l}50 \mathrm{mg} \text { twice weekly + narrow } \\
\text { band UVB (thrice weekly) }\end{array}$ & $84,9 \%$ & - & 46 \\
\hline
\end{tabular}

After 12 weeks of treatment, PASI-75 was achieved in $34 \%$ in patients receiving $25 \mathrm{mg}$ of etanercept twice weekly and in $49 \%$ of patients receiving $50 \mathrm{mg}$ twice weekly, compared with $3 \%$ of patients receiving placebo ( $P<0.001$ for both comparisons with the placebo group). ${ }^{13}$ After 24 weeks, response rates improved further to $45 \%$ of patients on $25 \mathrm{mg}$ twice weekly and to $54 \%$ in patients who had a dose reduction from $50 \mathrm{mg}$ twice weekly the first 12 weeks to $25 \mathrm{mg}$ the following 12 weeks. ${ }^{13}$ Similar results with etanercept monotherapy in psoriasis were consistently shown in another study: PASI-75 was $34 \%$ and $49 \%$ at 12 weeks and $44 \%$ and $59 \%$ at 24 weeks with etanercept $25 \mathrm{mg}$ twice weekly and $50 \mathrm{mg}$ twice weekly, respectively (no stepdown from $50 \mathrm{mg}$ to $25 \mathrm{mg}$ twice weekly occurred in this study after 12 weeks). ${ }^{6}$ Low dose etanercept ( $25 \mathrm{mg}$ once weekly) was clearly less effective with PASI-75 of $14 \%$ and $25 \%$ at 12 and 24 weeks respectively. ${ }^{6}$ An earlier phase 2 trial revealed a PASI-75 response of 30\% and $55 \%$ with etanercept $25 \mathrm{mg}$ twice weekly at week 12 and 24 respectively. ${ }^{14}$ Etanercept was generally well tolerated with similar incidence of adverse events in etanercept- vs placebo-treated patients with the exception of injectionsite reactions occurring more frequently with etanercept. 
Usually, these injection-site reactions were mild and only very rarely the reason for withdrawal from the study. ${ }^{6,13,14}$

Subgroup analysis based on an integrated database of the placebo-controlled part (first 12 weeks) of the three aforementioned studies ${ }^{6,13,14}$ indicated a tendency towards higher efficacy in the lower body weight group (below median of $89.36 \mathrm{~kg}$ ) and the higher baseline PASI (above median of 16): PASI-75 with etanercept $25 \mathrm{mg}$ twice weekly was $41 \%$ and $25 \%$ in the lower and higher weight subgroups and $37 \%$ and $29 \%$ in the higher and lower PASI-subgroups. ${ }^{16}$ The influence of body weight on etanercept effectiveness in psoriasis remains however highly controversial as clinical observations failed to show any correlation between body mass index and etanercept efficacy in psoriasis. ${ }^{17,18}$ The higher response to etanercept in the higher baseline PASI-subgroup ${ }^{16}$ is probably owing to the nonlinear nature of this scoring system with lower sensitivity in the lower PASI-range. ${ }^{19}$

Following etanercept discontinuation in patients who exhibited PASI-50 at week 24, a median time to relapse (defined as a loss of at least half of the improvement achieved between baseline and week 24) of 3 months was observed without cases of rebound flare (PASI increasing over $150 \%$ of baseline).$^{20}$ Moreover, etanercept retreatment of these relapsed patients at the initial dose, generated a similar response at 12 weeks indicating that psoriasis patients retain clinical response to etanercept on discontinuation and retreatment with the drug. ${ }^{20}$ A recently published long-term (54 weeks) study, in which continuous etanercept (25 mg twice weekly) therapy was compared with intermittent therapy (50 mg twice weekly for maximal 12 weeks or until interruption; $25 \mathrm{mg}$ twice weekly on reinitiation), confirmed that psoriasis patients continue to respond to etanercept along different cycles of discontinuation or reinitiation of the drug. ${ }^{21}$ In this study, the physician global assessment (PGA 0 to 5 score) was used to decide to discontinuation (PGA $\leq 2$ ) or reintroduction $(\mathrm{PGA} \geq 3$ ) of etanercept. Compared to PASI, PGA is quick and simple to use but its intrarater- and interrater reliability is inferior (intraclass correlation coefficient of 81 and 61 for PGA, compared to 96 and 91 for PASI). ${ }^{19}$ From baseline to week 54, the mean PASI decreased by $67,6 \%$ and $59,3 \%$ in the continuous and intermittent group, respectively. PASI-75 data were not disclosed. ${ }^{21}$

Although no direct head-to-head comparison study of etanercept with other TNF-inhibitors is available in psoriasis, the antipsoriatic effect of etanercept appears somewhat lower and clearly less speedy than that of infliximab and adalimumab. ${ }^{7}$ Very recently, the first head-to-head study of two biologics in psoriasis showed that etanercept $50 \mathrm{mg}$ biweekly for 12 weeks was less effective than ustekinumab (45 mg week 0 and 4), a fully human monoclonal antibody directed against the common p40 subunit of interleukin-23 and -12 (PASI-75 57\% and 68\% for etanercept and ustekinumab, respectively). ${ }^{22}$

\section{Alternative and new dosing schedules}

In view of etanercept's somewhat lower efficacy in psoriasis and higher frequency of administration as compared to other TNF-inhibitors (infliximab and adalimumab), ${ }^{7}$ alternative dosing schedules were developed in order to increase effectiveness and/or convenience for the patient.

A first strategy was to maintain a high etanercept dose (50 mg twice weekly) for a long-term (beyond the first 12 weeks). For that purpose, a placebo-controlled trial with open-label extension was designed in which patients were randomized to receive either placebo or etanercept (50 mg) biweekly for 12 weeks. After 12 weeks, patients who remained in the study received open-label etanercept (50 mg biweekly) for 84 weeks. ${ }^{23}$ After 12 and 24 weeks, $47 \%$ and $60 \%$ of patients displayed a PASI-75 response. The PASI-75 response reached its peak at week 48, with $63 \%$ for the placebo-etanercept group and $61.1 \%$ for the etanercept-etanercept group. The percentage of patients with a PASI-75 response after 96 weeks was $51.6 \%$ for the placebo-etanercept group and $51.1 \%$ for the etanercept-etanercept group. ${ }^{23}$ The exposure-adjusted event rates were similar for both groups after 96 weeks and did not increase with long-term exposure; injection-site reactions were more frequent in the etanercept-etanercept group. Hence, it was concluded that high-dose long-term etanercept is effective and well-tolerated in psoriasis. ${ }^{23}$ The high etanercept dose used in this study (50 mg twice weekly) is however not approved beyond the first 12 weeks of treatment of psoriasis. ${ }^{15}$

A second strategy consisted of the administration of high-dose etanercept $(50 \mathrm{mg})$ at a lower frequency (once weekly). An open-label extension study of the global phase 3 study with etanercept in psoriasis, ${ }^{13}$ investigated the effectiveness of etanercept $50 \mathrm{mg}$ once weekly vs $25 \mathrm{mg}$ twice weekly for 12 weeks in psoriasis patients who had received etanercept $25 \mathrm{mg}$ twice weekly for at least 24 weeks. ${ }^{24}$ It was demonstrated that efficacy (maintenance of PASI), pharmacokinetic profile (steady-state concentration over time, area under the curve and average concentration) and safety were comparable between etanercept $25 \mathrm{mg}$ twice weekly and $50 \mathrm{mg}$ once weekly. ${ }^{24}$ 
Based on these preliminary findings, a European, randomized, double-blind, placebo-controlled study was designed to assess the efficacy and safety of etanercept $50 \mathrm{mg}$ once weekly in 144 moderate-to-severe plaque psoriasis patients during 12 weeks. ${ }^{25}$ In an additional 12-week, open-label extension phase, all patients received etanercept $50 \mathrm{mg}$ once per week. 37,5\% of patients receiving etanercept $50 \mathrm{mg}$ once weekly achieved a PASI-75 response at week 12 , compared to $2.2 \%$ of patients in the placebo group. ${ }^{25}$ This PASI-75 response after 12 weeks with etanercept $50 \mathrm{mg}$ per week $(37,5 \%)$ is comparable if not slightly higher than that with etanercept $25 \mathrm{mg}$ twice weekly at week 12 in the two pivotal phase 3 trials ${ }^{6,13}$ and the phase $2 \operatorname{trial}^{14}(34 \%, 34 \%, 30 \%$, respectively). At week 24 following a 12-week open label period with etanercept $50 \mathrm{mg}$ once weekly, PASI-75 responders further climbed to $71,1 \%$ in the etanercept-etanercept group (24 weeks of etanercept) and $44,4 \%$ in the placebo-etanercept group (12 weeks of etanercept). ${ }^{25}$ The $71 \%$ PASI- 75 response after 24 weeks etanercept $50 \mathrm{mg}$ once weekly is well above that in earlier trials with etanercept $25 \mathrm{mg}$ twice a week (44\%, $45 \%, 55 \%)^{6,13,14}$ and even $50 \mathrm{mg}$ twice weekly $(59,60 \%){ }^{6,23}$ Possible explanations for this "outlier" include the open label design (raising high expectations with possibly increased "placebo effect" in patients and assessment bias in investigators in the second part of the study), the lower average body weight of the patients $(83.4 \mathrm{~kg}$ in this European study compared to approximately $90 \mathrm{~kg}$ in North-American studies) ${ }^{16}$ and the rather high mean baseline PASI in the current study (21.4 vs 18.8 in the North-American studies). ${ }^{16}$ Apart from the well-known injection-site reactions, no new safety signals were captured. ${ }^{25}$ In conclusion, the etanercept $50 \mathrm{mg}$ once a week treatment regimen was found to be very effective and well tolerated in psoriasis; hence, based on these study results, regulatory approval of this more patient-convenient etanercept dosing regimen (50 mg once weekly) was obtained in Europe for the treatment of psoriasis. ${ }^{15}$

\section{Etanercept in pediatric psoriasis}

A recent study evaluated the use of etanercept in 211 children and teenagers (aged 4 to 17 years) with moderate-to-severe plaque psoriasis (median PASI-score 16.4). ${ }^{26}$ This was the first large study of a systemic drug in pediatric psoriasis. Patients were injected once weekly with $0.8 \mathrm{mg} / \mathrm{kg}$ of etanercept up to a maximum of $50 \mathrm{mg}$. $57 \%$ of etanercepttreated patients achieved a PASI-75 response at week 12 , compared to $11 \%$ in the placebo group $(P<0.001){ }^{26}$ At week 24, PASI- 75 rose to $69 \%$. There were no reports of psoriasis rebound or change in psoriasis morphology during the withdrawal-retreatment period. ${ }^{26}$ The higher clinical response with etanercept (and placebo) in the pediatric population compared to adult psoriasis patients $\mathrm{s}^{6,13,14,25}$ may be partly explained by the often spontaneously remitting nature of pediatric psoriasis; in addition, the weight-based dosing of etanercept in children may be more effective than the fixed dosing in adults. Four serious adverse events occurred in three patients: ovarian cyst removal in one patient, gastroenteritis and gastroenteritis-associated dehydration in one patient, and pneumonia in one patient. All occurred in patients receiving open-label treatment, and all resolved without sequelae. ${ }^{26}$ Skin papilloma (presumably viral warts) was an adverse event that was encountered more commonly in etanercept-treated patients (16 events) than in the placebo group (no events). ${ }^{26}$ Based on this study, etanercept - as the first systemic agent - gained approval for the use of pediatric psoriasis from the age of 8 in Europe. ${ }^{15}$

\section{Etanercept combination therapy in psoriasis}

Combination therapy is a strategy that can be used to increase efficacy in recalcitrant disease (which is relevant for etanercept being the least potent anti-TNF medication for psoriasis), ${ }^{7}$ while reducing the risk for cumulative toxicity (eg, by dose reductions). The concept of cumulative toxicity is mainly derived from phototherapy (photocarcinogenesis) and systemic psoriasis therapies (nephrotoxicity for cyclosporine; hepatotoxicity for methotrexate). Hence, combination, rotational and sequential treatment strategies were developed for classical systemic agents for psoriasis..$^{27}$ Until recently, biologics were thought to be spared from cumulative toxicity as they do not cause organ toxicity (especially liver and kidney damage). But the recent market withdrawal of efalizumab, due to at least three cases of progressive multifocal leukoencephalopathy in psoriasis patients, all of whom on efalizumab for at least 3 years, brutally raised awareness about the possible cumulative toxicity of biologics. ${ }^{28}$ As etanercept is only approved in monotherapy for psoriasis, ${ }^{15}$ its combination with another systemic agent represents off-label use.

\section{Topical agents}

The use of topical agents (especially vitamin D analogues, steroids or a fixed combination of both) in combination with phototherapy or systemic drugs for psoriasis is beneficial and well documented. ${ }^{27}$ In clinical practice, topical drugs are also very commonly combined with biologics for 
psoriasis, including etanercept. ${ }^{29}$ Moreover, topical steroids of low-to-moderate strength were allowed on distinct areas (scalp, axilla, groin) in most of the psoriasis trials with etanercept. ${ }^{6,13,22,25,26}$ An expert consensus conference on etanercept treatment of psoriasis recommended the use of topical medication in combination with etanercept, especially at the start of therapy to increase the speed of therapeutic response. ${ }^{30}$ Nevertheless, formal evidence from published clinical trials combining a biologic with a topical agent is still very sparse and even lacking for etanercept. Very recently, a 16-week randomized controlled study in moderate-to-severe chronic plaque psoriasis was conducted to assess the efficacy of adalimumab plus calcipotriolbetamethasonedipropionate fixed-combination ointment vs adalimumab plus placebo ointment. ${ }^{31}$ The vitamin D-steroid fixed combination ointment accelerated the response to adalimumab during the first 4 weeks of treatment, but did not offer benefit beyond 4 weeks compared to adalimumab plus placebo ointment. ${ }^{31}$

\section{Acitretin}

Acitretin is a highly interesting candidate for combination therapy with biologics as it is not an immunosuppressive agent. Moreover, its chemopreventive properties against skin carcinogenesis $^{32}$ are of great value in the high risk moderateto-severe psoriasis population, where etanercept (like most other systemic psoriasis treatments) appears to increase the risk for squamous cell carcinoma. ${ }^{33}$ A recent Italian 24-week pilot study on 60 patients with moderate-to-severe chronic plaque psoriasis demonstrated that the addition of acitretin $0.4 \mathrm{mg} / \mathrm{kg} /$ day to etanercept $25 \mathrm{mg}$ once weekly was as effective (PASI-75 44\%) as etanercept $25 \mathrm{mg}$ twice weekly (PASI-75 45\%). ${ }^{34}$ Based on these data, acitretin can be viewed as 'etanercept-sparing' and costreducing. As the combination of acitretin with etanercept at its normal dosing regimen was not performed in this trial, it remains unclear whether acitretin is able to bring etanercept's effectiveness to a higher level. A retrospective review of 15 psoriasis patients treated with concomitant acitretin (10 to $50 \mathrm{mg} /$ day) and biologics (etanercept in 4 patients) concluded that this scheme was promising for the management of refractory psoriasis. ${ }^{35}$ Similar reports on acitretin-etanercept combination in psoriasis were described in two case series. ${ }^{29,36}$ Finally, a stable dose of acitretin ( $\leq 50 \mathrm{mg} /$ day) was allowed in a recent study of continuous vs paused etanercept therapy of psoriasis ${ }^{21}$ (see section on effectiveness of etanercept monotherapy above for a brief outline of this study).

\section{Methotrexate}

Etanercept-methotrexate combination therapy is well established to increase efficacy in rheumatologic patients with insufficient response to monotherapy with either of the agents. ${ }^{37}$ Consequently, psoriasis patients with concomitant poorly controlled psoriatic arthritis may benefit from this combination. Furthermore, methotrexate can also be combined with TNF-antibodies such as infliximab in order to reduce the formation of neutralizing antibodies to the TNF-antagonist. ${ }^{38}$ A recent Scandinavian 24-week study in 59 psoriasis patients with inadequate response to methotrexate monotherapy compared etanercept in combination with a stable methotrexate dose with etanercept in combination with a tapered methotrexate dose (gradual tapering and discontinuation over the first 4 weeks of the trial). ${ }^{39}$ Etanercept was administered at a dose of $50 \mathrm{mg}$ twice weekly the first 12 weeks, followed by $25 \mathrm{mg}$ twice weekly for the remaining 12 weeks. At week 24 , a significantly higher portion of patients $(70 \%)$ achieved PASI-75 in the group with stable methotrexate dose than in the methotrexate-tapered group (37\%). ${ }^{39}$ A case series with six psoriasis patients showed that etanercept may be used as a means of tapering methotrexate while maintaining good clinical control. The patients received methotrexate at a starting dose of $10 \mathrm{mg}$ per week with incremental increases to achieve a PASI-50 response. Etanercept was then added (50 mg/week) and methotrexate tapered by $2.5 \mathrm{mg} /$ week every 2 to 4 weeks until discontinued. ${ }^{40}$ The PASI-50 response on methotrexate monotherapy was $56.3 \%$. This clinical improvement was sustained in 3 of 6 patients after discontinuation of methotrexate. Two patients had a relapse of psoriasis (loss of at least $50 \%$ of PASI improvement) when methotrexate was stopped but this was resolved by increasing etanercept to $50 \mathrm{mg}$ twice weekly. ${ }^{40} \mathrm{~A}$ Dutch case series demonstrated that the introduction of methotrexate to psoriasis patients with insufficient response to etanercept resulted in clear improvement in 4 of 6 patients..$^{41}$ In addition, 5 of 6 patients, who were already on methotrexate before the introduction of etanercept and who subsequently discontinued methotrexate, experienced a decrease in PASI improvement. ${ }^{41}$ In the same centre, methotrexate appeared to be the systemic agent that was most frequently combined with etanercept. ${ }^{29}$ In a recent study of continuous vs paused etanercept therapy of psoriasis, patients were allowed to continue a stable dose of methotrexate ( $\leq 20 \mathrm{mg} /$ week). ${ }^{21}$ In the aforementioned studies, tolerability of etanercept-methotrexate combination was good and there were no signs of increased toxicity on the short term. ${ }^{39,40}$ Long-term safety of etanercept-methotrexate combination therapy is obviously a major concern but it is 
reassuring that a 2-year study in more than 500 rheumatoid arthritis patients did not reveal increased toxicity (including serious infectious and non-infectious adverse events) in the etanercept-methotrexate combination group vs etanercept or methotrexate monotherapy groups. ${ }^{42}$

\section{Cyclosporine}

Despite the incidental use of cyclosporine-etanercept combination therapy in high-need psoriasis patients, ${ }^{29}$ this combination is not recommended from a safety perspective. Apart from being an immunosuppressive, cyclosporine also induces cancer progression in mice, independently from its immune effects. ${ }^{43}$ These theoretical considerations together with the absence of clinical safety data warrant great caution for the combination of cyclosporine with TNF-inhibitors (including etanercept), which probably bear an increased risk for severe infection and malignancy (including skin cancer) themselves. ${ }^{33,44,45}$

\section{Phototherapy}

A recently published, multicenter, open-label, single arm study investigated the antipsoriatic effect of narrow bandUVB (thrice weekly) in combination with etanercept (50 mg twice weekly) in 86 plaque psoriasis patients. An impressive $84.9 \%$ of patients achieved PASI-75 at week $12 .{ }^{46}$ Similarly, a small, prospective, randomized, half-side study was conducted in 5 psoriasis patients who did not exhibit a PASI-75 response after 6 weeks of etanercept $50 \mathrm{mg}$ twice weekly. A random half-side of the body was treated with narrow-band UVB in the next 6 weeks while continuing etanercept at an unchanged dose. At week 12, the mean PASI reduction (based on half-side PASI) was $89 \%$ at irradiated vs $68 \%$ at nonirradiated body side. ${ }^{47}$

Despite increased efficacy along with a good safety and tolerability profile on the short term, ${ }^{46,47}$ TNF-inhibitor-UVB combination therapy raises strong safety concerns from the long-term perspective. This vision is based on the highly controversial and unclarified role of TNF in epidermal carcinogenesis: on the one hand, TNF-knockout mice are resistant to chemical skin carcinogenesis ${ }^{48}$ but at the same time TNF is a critical factor for tumor immune surveillance. ${ }^{49}$ Indeed, knowing that UV-dependent DNA damage induces TNF, ${ }^{50}$ and that UVB-induced TNF mediates apoptosis in keratinocytes $^{51}$, induction of TNF by UVB may represent a mechanism to eliminate mutated (precancerous) cells. This view is underscored by the increased risk of squamous cell carcinoma in psoriasis patients receiving etanercept. ${ }^{33}$ Until the uncertainty about the role of TNF in photocarcinogenesis is fully resolved by preclinical research, it is therefore more cautious not to combine TNF-inhibitors with phototherapy.

\section{Conclusion}

The initially approved dosing for etanercept in psoriasis consisted of $25 \mathrm{mg}$ twice weekly in repeated 24-week cycles with the possibility of doubling the dose in the very first 12 weeks. Recently a new dosing schedule of etanercept $50 \mathrm{mg}$ once weekly was approved based on a PASI-75 of $37 \%$ and $71 \%$ at week 12 and 24 . Etanercept was also approved in children with psoriasis from the age of 8 at a dosing of $0.8 \mathrm{mg} / \mathrm{kg}$ (up to $50 \mathrm{mg}$ ) once weekly resulting in a PASI-75 of 57\% and 69\% following 12 and 24 weeks of treatment. Several small clinical trials and case series have shown increased efficacy of etanercept in combination with acitretin, methotrexate or UVB, whereas data are lacking for the combination with cyclosporine or topical drugs. From a safety perspective, the combination with acitretin (nonimmunosuppressive) or methotrexate (long-term safety data in rheumatology) are interesting, whereas the combination with cyclosporine or phototherapy holds a theoretical risk for increased (photo)carcinogenesis.

\section{Disclosures}

S Segaert has been a speaker and/or consultant for Abbott, Amgen, Leo Pharma, Merck-Serono, Schering-Plough and Wyeth.

\section{References}

1. Carswell EA, Old LJ, Kassel RL, Green S, Fiore N, Williamson B. An endotoxin-induced serum factor that causes necrosis of tumors. Proc Natl Acad Sci U S A. 1975;72:3666-3670.

2. Schottelius AJG, Moldawer LL, Dinarello CA, Asadullah K, Sterry W, Edwards III CK. Biology of tumor necrosis factor-alpha-implications for psoriasis. Exp Dermatol. 2004;13:193-222.

3. Oh CJ, Das KM, Gottlieb AB. Treatment with anti-tumor necrosis factor $\alpha$ (TNF- $\alpha$ ) monoclonal antibody dramatically decreases the clinical activity of psoriasis lesions. J Am Acad Dermatol. 2000;42:829-830.

4. Bonifati C, Carducci M, Cordiali Fei P, et al. Correlated increases of tumour necrosis factor-alpha, interleukin- 6 and granulocyte monocyte-colony stimulating factor levels in suction blister fluids and sera of psoriatic patients-relationships with disease severity. Clin Exp Dermatol. 1994;19:383-387.

5. Mussi A, Bonifati C, Carducci M, et al. Serum TNF-alpha levels correlate with disease severity and are reduced by effective therapy in plaque-type psoriasis. J Biol Regul Homeost Agents. 1997;11: 115-118.

6. Leonardi CL, Powers JL, Matheson RT, et al. Etanercept as monotherapy in patients with psoriasis. $N$ Engl J Med. 2003;349:2014-2022.

7. Menter A, Gottlieb A, Feldman SR, et al. Guidelines of care for the management of psoriasis and psoriatic arthritis: Section 1. Overview of psoriasis and guidelines of care for the treatment of psoriasis with biologics. J Am Acad Dermatol. 2008;58:826-850.

8. Scallon B, Cai A, Solowski N, et al. Binding and functional comparisons of two types of tumor necrosis factor antagonists. $J$ Pharmacol Exp Ther. 2002;301:418-426. 
9. Sandborn WJ, Hanauer SB, Katz S, et al. Etanercept for active Crohn's disease: a randomized, double-blind, placebo-controlled trial. Gastroenterology. 2001;121:1088-1094.

10. Wegener's Granulomatosis Etanercept Trial (WGET) Research Group. Etanercept plus standard therapy for Wegener's granulomatosis. $N$ Engl J Med. 2005;352:351-361.

11. Wallis RS, Broder MS, Wong JY, Hanson ME, Beenhouwer DO. Granulomatous infectious diseases associated with tumor necrosis factor antagonists. Clin Infect Dis. 2004;38:1261-1265.

12. Pang ML, Nguyen TU, Koo JYM. Etanercept for treatment of psoriasis. In: Koo JYM, Lee CS, Lebwohl MG, Weinstein GD, Gottlieb A, ed. Moderate-to-severe Psoriasis, third edition. New York: Informa Healthcare; 2009:259-272.

13. Papp KA, Tyring S, Lahfa M, et al. A global phase III randomized controlled trial of etanercept in psoriasis: safety, efficacy, and effect of dose reduction. Br J Dermatol. 2005;152:1304-12.

14. Gottlieb AB, Matheson RT, Lowe N, et al. A randomized trial of etanercept as monotherapy for psoriasis. Arch Dermatol. 2003;139: $1627-1632$.

15. Enbrel ${ }^{\circledR}$ summary of product characteristics. www.emea.europa.eu/ humandocs/PDFs/EPAR/Enbrel/H-262-PI-en.pdf

16. Gordon K, Korman N, Frankel E, et al. Efficacy of etanercept in an integrated multistudy database of patients with psoriasis. $J$ Am Acad Dermatol. 2006;54:S101-S111.

17. De Groot M, Appelman M, Spuls PI, de Rie MA, Bos J. Initial experience with routine administration of etanercept in psoriasis. $\mathrm{Br} J$ Dermatol. 2006;155:808-814.

18. Esposito M, Mazzotta A, Saraceno R, Schipani C, Chimenti S. Influence and variation of the body mass index in patients treated with etanercept for plaque-type psoriasis. Int J Immunopathol Pharmacol. 2009;22:219-225.

19. Berth-Jones J, Thompson J, Papp K, et al. A study examining interrater and intrarater reliability of a novel instrument for assessment of psoriasis: the Copenhagen Psoriasis Severity Index. $\mathrm{Br} J$ Dermatol. 2008; 159:407-412.

20. Gordon KB, Gottlieb AB, Leonardi CL, et al. Clinical response in psoriasis patients discontinued from and then reinitiated on etanercept therapy. J Dermatol Treat. 2006;17:9-17.

21. Ortonne JP, Griffiths C, Daudén E, et al. Efficacy and safety of continuous vs paused etanercept treatment in patients with moderateto-severe psoriasis over 54 weeks: the CRYSTEL study. Exp Rev Dermatol. 2008;3:657-665.

22. Griffiths CEM, Strober B, van de Kerkhof PCM, et al. A phase 3, multicenter, randomized study comparing ustekinumab and etanercept for the treatment of moderate to severe plaque psoriasis. Poster presented at 17th congress of the European Adademy of Dermatology and Venerology; 2008 September 17-21, Paris France. Poster FP1336.

23. Tyring S, Gordon KB, Poulain Y, et al. Long-term safety and efficacy of $50 \mathrm{mg}$ of etanercept twice weekly in patients with psoriasis. Arch Dermatol. 2007;143:719-726.

24. Elewski B, Leonardi C, Gottlieb AB, et al. Comparison of clinical and pharmacokinetic profiles of etanercept $25 \mathrm{mg}$ twice weekly and $50 \mathrm{mg}$ once weekly in patients with psoriasis. Br J Dermatol. 2007;156: $138-142$.

25. Van de Kerkhof PCM, Segaert S, Lahfa M, et al. Once weekly administration of etanercept $50 \mathrm{mg}$ is efficacious and well tolerated in patients with moderate-to-severe plaque psoriasis: a randomized controlled trial with open-label extension. Br J Dermatol. 2009;159: 1177-1185.

26. Paller AS, Siegfried EC, Langley RG, et al. Etanercept treatment for children and adolescents with plaque psoriasis. $N$ Engl $J$ Med. 2008;358:241-251.

27. Lebwohl M, Menter A, Koo J, Feldman SR. Combination therapy to treat moderate to severe psoriasis. J Am Acad Dermatol. 2004;50: 416-430.

28. www.emea.europa.eu/humandocs/PDFs/EPAR/raptiva/2085709en.pdf.
29. Driessen RJB, Berends MAM, Boezeman JB, van de Kerkhof PCM, De Jong EMGJ. Psoriasis treatment with etanercept and efalizumab: clinical strategies influencing treatment outcome. $\mathrm{Br} J$ Dermatol. 2008;158:1098-1106.

30. Boehncke WH, Brasie RA, Barker J, et al. Recommendations for the use of etanercept in psoriasis: a European dermatology expert group consensus. J Eur Acad Dermatol Venereol. 2006;20:988-998.

31. Thaçi D, Khemis A, Chimenti S, et al. Efficacy and safety of adalimumab plus topical therapy (calcipotriol/betamethasone) in the treatment of moderate to severe psoriasis - first results of Believe study. Presented at 6th EADV Spring Symposium; 2009 April 23-26, Bucharest Romania. Abstract FC07.5.

32. McKenna DB, Murphy GM. Skin cancer chemoprophylaxis in renal transplant recipients: 5 years of experience using low-dose acitretin. Br J Dermatol. 1999;140:656-660.

33. Gottlieb AB, Gordon KB, Giannini EH, et al. Malignancies from patients receiving etanercept across indications. [abstract] Ann Rheum Dis. 2008;67 Suppl II:322.

34. Gisondi P, Del Giglio M, Cotena C, Girolomoni G. Combining etanercept and acitretin in the therapy of chronic plaque psoriasis: A 24-week, randomized, controlled, investigator-blinded pilot trial. Br J Dermatol. 2008;58:1345-1349.

35. Smith ECA, Riddle C, Menter MA, Lebwohl M. Combining systemic retinoids with biologic agents for moderate to severe psoriasis. Int $J$ Dermatol. 2008;47:514-518.

36. Conley J, Nanton J, Dhawan S, Pierce DJ, Feldman SR. Novel combination regimens: Biologics and acitretin for the treatment of psoriasis a case series. J Dermatol Treat. 2006;17:86-89.

37. Van der Heijde, Burmester G, Melo-Gomes J, et al. The safety and efficacy of adding methotrexate to etanercept in moderately active rheumatoid arthritis patients previously treated with monotherapy. Ann Rheum Dis. 2008;67:182-188.

38. Baert F, Noman M, Vermeire S, et al. Influence of immunogenicity on the long-term efficacy of infliximab in Crohn's disease. $N$ Engl J Med. 2008;348:601-608.

39. Zachariae C, Mork NJ, Reunala T, et al. The combination of etanercept and methotrexate increases the effectiveness of treatment in active psoriasis despite inadequate effect of methotrexate therapy. Acta Derm Venereol. 2008;88:495-501.

40. Yamauchi PS, Lowe NJ. Etanercept therapy allows the tapering of methotrexate and sustained clinical responses in patients with moderate to severe psoriasis. Int J Dermatol. 2008;47:202-204.

41. Driessen RJB, van de Kerkhof PCM, De Jong EMGJ. Etanercept combined with methotrexate for high-need psoriasis. Br J Dermatol. 2008;159:460-463.

42. Van der Heijde D, Klareskog L, Rodriguez-Valverde V, et al. Comparison of etanercept and methotrexate, alone and combined, in the treatment of rheumatoid arthritis. Two-year clinical and radiographic results from the TEMPO study, a double-blind, randomized trial. Arthitis Rheum. 2006;54:1063-1074.

43. Hojo M, Morimoto T, Maluccio M, et al. Cyclosporine induces cancer progression by a cell-autonomous mechanism. Nature. 1999;397: 530-534.

44. Bongartz T, Suton AJ, Sweeting MJ, Buchan I, Matteson EL, Montori V. Anti-TNF antibody therapy in rheumatoid arthritis and the risk of serious infections and malignancies: systematic review and metaanalysis of rare harmful effects in randomized controlled trials. JAMA. 2006;295:2275-2285.

45. Bongartz T, Warren FC, Mines D, Matteson EL, Abrams KR, Sutton AJ. Etanercept therapy in rheumatoid arthritis and risk of malignancies. A systematic review and individual patient data metaanalysis of randomized controlled trials. Ann Rheum Dis. 2009;68: 1177-1183.

46. Kircik L, Bagel J, Korman N, et al. Utilization of narrow-band ultraviolet light $\mathrm{B}$ therapy and etanercept for the treatment of psoriasis (UNITE): efficacy, safety and patient-reported outcomes. $J$ Drugs Dermatol. 2008;7:245-253. 
47. Wolf $\mathrm{P}$, Hofer A, Legat FJ, et al. Treatment with 311-nm ultraviolet $\mathrm{B}$ accelerates and improves the clearance of psoriatic lesions in patients treated with etanercept. Br J Dermatol. 2009;160:186-189.

48. Moore RJ, Owens DM, Stamp G, et al. Mice deficient in tumor necrosis factor- $\alpha$ are resistant to skin carcinogenesis. Nat Med. 1999; 5:828-831.

49. Calzascia T, Pellegrini M, Hakan H, et al. TNF- $\alpha$ is critical for antitumor but not antiviral $\mathrm{T}$ cell immunity in mice. $J$ Clin Invest. 2007; 117:3833-3845.
50. Kibitel J, Hejmadit V, Alas L, O'Connor A, Sutherland BM, Yarosh D. UV-DNA damage in mouse and human cells induces the expression of tumor necrosis factor $\alpha$. Photochem Photobiol. 2008;67:541-546.

51. Schwarz A, Bhardwaj R, Aragane Y, et al. Ultraviolet-B-induced apoptosis of keratinocytes: evidence for partial involvement of tumor necrosis factor-alpha in the formation of sunburn cells. $J$ Invest Dermatol. 1995;104:922-927.

\section{Publish your work in this journal}

The Journal of Inflammation Research is an international, peer-reviewed open-access journal that welcomes laboratory and clinical findings on the molecular basis, cell biology and pharmacology of inflammation including original research, reviews, symposium reports, hypothesis formation and commentaries on: acute/chronic inflammation; mediators of inflamma- tion; cellular processes; molecular mechanisms; pharmacology and novel anti-inflammatory drugs; clinical conditions involving inflammation. The manuscript management system is completely online and includes a very quick and fair peer-review system. Visit http://www.dovepress.com/ testimonials.php to read real quotes from published authors.

Submit your manuscript here: http://www.dovepress.com/journal-of-inflammation-research-journal 